\title{
Microwave-Assisted Synthesis and Processing of Al-Doped, Ga- Doped, and Al, Ga Codoped ZnO for the Pursuit of Optimal Conductivity for Transparent Conducting Film Fabrication
}

D. S. Y. Jayathilake, ${ }^{\dagger}$ T. A. Nirmal Peiris, ${ }^{\dagger}$ Jagdeep S. Sagu, ${ }^{\dagger}$ Dominic B. Potter, ${ }^{\S}$ K. G. U. Wijayantha, ${ }^{*},{ }^{\dagger}$ C. J. Carmalt, ${ }^{\S(0)}$ and D. J. Southee ${ }^{\dagger, \ddagger}$

${ }^{\dagger}$ Energy Research Laboratory, Department of Chemistry, and ${ }^{\ddagger}$ Design School, Loughborough University, Loughborough LE11 3TU, U.K.

${ }^{\S}$ Department of Chemistry, 20 Gordon Street, University College London, London WC1H 0AJ, U.K.

Supporting Information

ABSTRACT: This work reports the microwave-assisted fabrication of highly conducting Al-doped $\mathrm{ZnO}$ (AZO), Gadoped $\mathrm{ZnO}$ (GZO), and $\mathrm{Al}$, Ga codoped $\mathrm{ZnO}$ (AGZO) materials as cheaper earth abundant alternatives to indium tin oxide (ITO) for transparent conducting applications. All three doped $\mathrm{ZnO}$ powder samples were compressed into pellets, and their electrical properties were evaluated after the postsynthesis heat treatment. The heat treatment was performed by sintering the pellets at $600{ }^{\circ} \mathrm{C}$ in a reducing atmosphere using either conventional radiant annealing for $3 \mathrm{~h}$ or microwave annealing for $90 \mathrm{~s}$. The $\mathrm{Al}$ and $\mathrm{Ga}$ dopant levels were systematically varied from 0.5 to 2.5 at. \%, and it was found that the lowest resistivity values for the pelleted singly doped

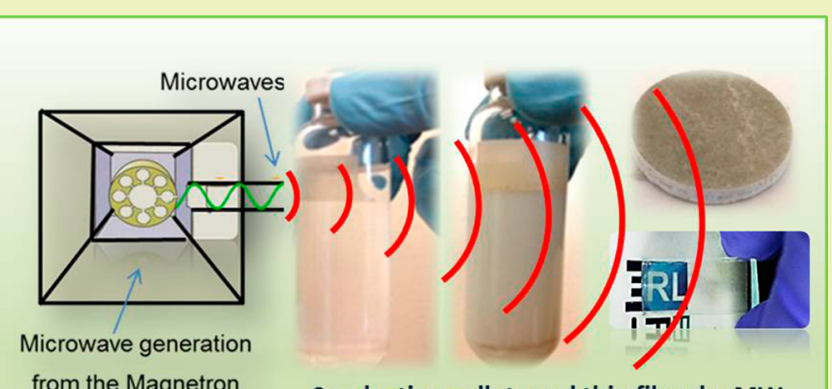

from the Magnetron
Conducting pellets and thin films by MW synthesized doped $\mathrm{ZnO}$ powders

$\mathrm{ZnO}$ powders exist when the doping level is adjusted to 1.5 at. \% for both $\mathrm{AZO}$ and GZO, giving resistivity values of $4.4 \times 10^{-3}$ and $4.3 \times 10^{-3} \Omega \cdot \mathrm{cm}$, respectively. The lowest resistivity of $5.6 \times 10^{-4} \Omega \cdot \mathrm{cm}$ was achieved for the pelleted codoped AGZO powder using the optimized $\mathrm{Al}$ and $\mathrm{Ga}$ dopant levels. Notably, this value is one magnitude lower than the best literature reported value for conventionally synthesized codoped AGZO powder. The resistivity values obtained for the pellets after radiant and microwave postsynthesis heat treatment are comparable, although the microwave heat treatment was performed only for $90 \mathrm{~s}$, compared to $3 \mathrm{~h}$ for conventional radiant heat treatment. Hence, significant gains were made in the postannealing step by reducing time, cost, and energy required, benefiting our thrust for finding sustainable routes toward alternative low-cost transparent conducting oxides. As a proof of concept, transparent conducting thin films were fabricated via a simple aerosolassisted deposition technique using our best conducting AGZO nanoparticles. The films exhibited a visible transmittance as good as $90 \%$ and a resistivity of $5.7 \times 10^{-3} \Omega \cdot \mathrm{cm}$, which can compete with the existing high cost ITO films.

KEYWORDS: Transparent conducting oxides, AZO, GZO, AGZO, Microwaves, Synthesis, Processing, Thin films

\section{INTRODUCTION}

Transparent conducting oxides (TCOs) are of great importance in modern life due to their applications as coatings in electronic and optoelectronic devices such as solar cells, touch screen displays, flat panel displays, automobile/aircraft windows, and organic light emitting diodes (OLEDs). ${ }^{1}$ Typically, indium tin oxide (ITO) is the TCO of choice; however, the cost of ITO has steadily increased recently due to the rarity of In. Therefore, research has intensified to find sustainable alternatives to ITO, with doped $\mathrm{ZnO}$ showing many favorable characteristics, most notably low cost. Various methods, including coprecipitation, hydrothermal processes, sol-gel, spray pyrolysis, aerosol-assisted methods, pulsed laser deposition, and magnetron sputtering, have been widely used to develop $\mathrm{ZnO}$ based TCOs. $^{2-5}$
Controlling atomic level doping during the synthesis of $\mathrm{ZnO}$ is challenging due to native defects present in the hexagonal wurtzite structure, which alter the optical and electrical properties of the material. ${ }^{6-8}$ Structural defects also can be dependent on the atmosphere in which the $\mathrm{ZnO}$ material is grown and the postsynthesis heat treatment., 10 Oxygen vacancies can be filled or manipulated by changing the annealing atmosphere. For instance, annealing under an $\mathrm{O}_{2}$ atmosphere could reduce the number of oxygen vacancies in the lattice and hence cause a reduction in the number of charge carriers present in $\mathrm{ZnO}$ films. ${ }^{6}$ On the other hand, annealing under reductive atmospheres (i.e., $\mathrm{H}_{2}$-rich atmospheres)

Received: January 23, 2017

Revised: April 6, 2017

Published: April 11, 2017 
increases the $n$-type conductivity of $\mathrm{ZnO}$ by passivating the $\mathrm{Zn}$ vacancies. ${ }^{11}$ In this condition, hydrogen also can be substituted on an oxygen site and form a multicenter bond with the four nearest-neighbor $\mathrm{Zn}$ atoms. The substitutional hydrogen has a low formation energy and acts as a shallow donor. ${ }^{12}$ Additionally, zinc interstitials can form complexes with ambient nitrogen, which act as shallow donors to further increase the conductivity of $\mathrm{ZnO}^{13}$ Alongside atmospheric conditions, annealing time and temperature are two other parameters that can have an influence on the electrical properties of doped $\mathrm{ZnO}$ films. ${ }^{14,15,8,16}$ Even though these effects are extensively reported by many researchers, the exact effect of the annealing time on the structural and optoelectronic properties of doped $\mathrm{ZnO}$ is still unclear and widely debated.

Extensive efforts have been undertaken to improve the transparent conducting properties of $\mathrm{ZnO}$, and it has been shown that various elements, such as $\mathrm{Al}, \mathrm{Ga}, \mathrm{Cu}$, In, or Se, can be used as dopants which considerably enhance the electrical properties of $\mathrm{ZnO} .^{17} \mathrm{Al}$-doped $\mathrm{ZnO}(\mathrm{AZO})$ has shown poor humidity stability compared to Ga-doped $\mathrm{ZnO}$ (GZO). However, conducting GZO is not an ideal alternative TCO due to the high cost associated with Ga. ${ }^{18,19}$ Therefore, research has focused on the codoping of $\mathrm{ZnO}$ with $\mathrm{Al}$ and $\mathrm{Ga}$ (AGZO) as a sustainable TCO material with enhanced electrical properties. For instance, both $\mathrm{Al}$ and $\mathrm{Ga}$ are simultaneously introduced into the $\mathrm{ZnO}$ structure as dopants. Zhang et al. investigated the structural and electronic properties of AGZO powders synthesized by chemical coprecipitation. They observed a smaller grain size in AGZO powders compared to $\mathrm{AZO}$, suggesting that the codoped material is better for high quality ceramic target preparation. Their sintered AGZO pellets exhibited a resistivity of $2.518 \times 10^{-3} \Omega \cdot \mathrm{cm} \cdot{ }^{20}$ Furthermore, a resistivity value of $9.0 \times 10^{-3} \Omega \cdot \mathrm{cm}$ was reported for AGZO powder synthesized using the continuous hydrothermal flow synthesis (CHFS) method followed by sintering the pellets by conventional radiant annealing under $5 \% \mathrm{H}_{2} / \mathrm{N}_{2}$ gas flow at 500 ${ }^{\circ} \mathrm{C}$ for $3 \mathrm{~h}^{21}$

In recent years, a great deal of interest has been generated for the synthesis of materials under the irradiation of microwaves as an alternative advanced material synthesis technique. Volumetric heating by microwave radiation leads to fast reaction rates, and rapid and uniform heating throughout the reaction mixture, which cannot be achieved by conventional radiant annealing methods. Heat generation in materials by microwave energy is fundamentally different from conventional radiant heating, conduction, or convection heating. In the microwave process, heat is generated within the material itself, instead of originating from external heating elements. In other words, microwave heat generation is due to an energy conversion process rather than a heat transfer process. Thus, the microwave synthesis technique has produced inorganic materials with unique properties that cannot be achieved by other methods which use conventional thermal processing. ${ }^{22}$

Recent reports indicate that microwave-synthesized TCO materials possess significantly improved conducting properties by enhancing crystallinity and modifying the intrinsic defects. For example, Feldmann et al. reported the microwave synthesis of ITO and AZO pelleted powders in polyol media with resistivity values of $1.1 \times 10^{-2} \Omega \cdot \mathrm{cm}$ and $5.1 \times 10^{-1} \Omega \cdot \mathrm{cm}$, respectively. ${ }^{23,24}$ Niederberger et al. synthesized AZO by a microwave-assisted nonaqueous sol-gel route in benzyl alcohol and then processed it into a TCO thin film. They reported a minimum resistivity value of $2.35 \times 10^{-2} \Omega \cdot \mathrm{cm}$ for their AZO thin film after postsynthesis heat treatment. ${ }^{25}$ However, to the best of our knowledge, there are very few literature reports available on microwave-assisted synthesis of TCOs.

In this study, we synthesized conducting AZO, GZO, and codoped AGZO powders by a single-step microwave-assisted synthesis method. The conductivity of the powders was tuned by varying the $\mathrm{Al}$ and $\mathrm{Ga}$ dopant amounts. The lowest resistivity values of $5.6 \times 10^{-4} \Omega \cdot \mathrm{cm}$ and $5.7 \times 10^{-3} \Omega \cdot \mathrm{cm}$ were achieved for $\mathrm{Al}(1.5$ at. \%) and $\mathrm{Ga}(1.5$ at. \%) codoped pellets and thin films, respectively. Furthermore, the resistivity and the transparency of the AGZO thin film reported in this work show promising signs of utilizing this cost-effective alternative to replace expensive ITO.

\section{EXPERIMENTAL METHODS}

Powder Synthesis. AZO, GZO, and AGZO powders were prepared by microwave synthesis. In this method, $\mathrm{Zn}\left(\mathrm{CH}_{3} \mathrm{COO}\right)$. $2 \mathrm{H}_{2} \mathrm{O}(1.00 \mathrm{~g})$ (BDH Chemicals) was used as the $\mathrm{ZnO}$ precursor. Appropriate atomic percentages of $\mathrm{Al}^{3+}$ and $\mathrm{Ga}^{3+}$ were added to the $\mathrm{ZnO}$ precursor in the form of $\mathrm{AlCl}_{3} \cdot 6 \mathrm{H}_{2} \mathrm{O}$ (Sigma-Aldrich) and $\mathrm{Ga}\left(\mathrm{NO}_{3}\right)_{3} \cdot x \mathrm{H}_{2} \mathrm{O}$ (Sigma-Aldrich), which were dissolved in diethylene glycol (DEG) $(45 \mathrm{~mL})$ (Sigma-Aldrich) and deionized water $(5 \mathrm{~mL})$. The solution was stirred for $1 \mathrm{~h}$ to obtain a clear, transparent solution. The clear solution was transferred to a fluorocarbon polymer (TFM) vessel after purging with Ar for $5 \mathrm{~min}$. The vessel was sealed after purging with Ar prior to being placed in the microwave synthesizer (Anton Paar Multiwave PRO, $2.45 \mathrm{GHz}, 1500 \mathrm{w}$ ) at $200{ }^{\circ} \mathrm{C}$ for $30 \mathrm{~min}$. The microwave heating ramp rate was $20^{\circ} \mathrm{C} / \mathrm{min}$, and the timing of the reaction was started when the vessel reached the desired temperature of $200{ }^{\circ} \mathrm{C}$. After the reaction was completed, the vessel was allowed to cool to room temperature before removal of the reaction product mixture from the microwave reactor. Temperature, pressure, and microwave power profiles for a typical reaction are given in the Supporting Information in Figure S1. After the reaction had taken place, the clear reaction solution mixture had transformed to an opaque suspension, which was then centrifuged, washed with ethanol, and placed in an oven at $60{ }^{\circ} \mathrm{C}$ for $1 \mathrm{~h}$ to evaporate the solvent completely. The dried powder was annealed at $450{ }^{\circ} \mathrm{C}$ for another hour using a hot plate. The powders were then compressed into pellets using a Specac manual hydraulic press under a 10 ton load. The annealed, metal-doped powder was then used to prepare pellets. Figure S2 provides a step-by-step scheme of microwave synthesis of doped $\mathrm{ZnO}$ powder.

Postsynthesis Heat Treatment of Pellets. The pellets prepared using microwave-synthesized AZO, GZO, and AGZO powders were treated by both conventional radiant and microwave-assisted heating techniques. Conventional radiant heating was conducted in a tube furnace (MTF-10-25-130, Carbolite, UK) with a ramp rate of $15{ }^{\circ} \mathrm{C}$ $\mathrm{min}^{-1}$ to $600{ }^{\circ} \mathrm{C}$ and then held for $3 \mathrm{~h}$ under a steady $5 \% \mathrm{H}_{2} / \mathrm{N}_{2}$ flow of $1825 \mathrm{~mL} \cdot \mathrm{min}^{-1}$ before allowing cool down to room temperature under the same gas flow. The microwave-assisted annealing was carried out using a microwave oven (Microwave research Applications Inc. BP-211/50, USA) operating at $2.45 \mathrm{GHz}$ frequency with a maximum power of $3000 \mathrm{~W}$. The microwave heat treatment was facilitated by using $\mathrm{SiC}$ susceptor tiles, placed on both sides of the doped $\mathrm{ZnO}$ pellets. The heat loss was minimized by shielding the sample within thermally insulating blocks. ${ }^{26,27}$ The pellets, SiC tiles, and insulating blocks were placed inside a custom-made quartz vessel fitted with a gas inlet and outlet and a zirconium oxide window to allow monitoring of the temperature using an IR thermometer. Prior to the microwave annealing, the quartz vessel containing the TCO pellet was purged with the $5 \% \mathrm{H}_{2} / \mathrm{N}_{2}$ gas mixture at $1825 \mathrm{~mL} \mathrm{~min}^{-1}$ (BOC, UK) for $5 \mathrm{~min}$. The microwave heat treatment was provided under a constant gas flow of $5 \% \mathrm{H}_{2} / \mathrm{N}_{2}$ for $90 \mathrm{~s}$. During the heat treatment, the temperature of the $\mathrm{SiC}$ susceptor was monitored using an infrared temperature probe (Mikron infrared Inc. M67/M67S series, USA) with an error of $\pm 5^{\circ} \mathrm{C}$. After $90 \mathrm{~s}$, the temperature of the susceptor reached $600{ }^{\circ} \mathrm{C}$. Once the $90 \mathrm{~s}$ microwave annealing step 

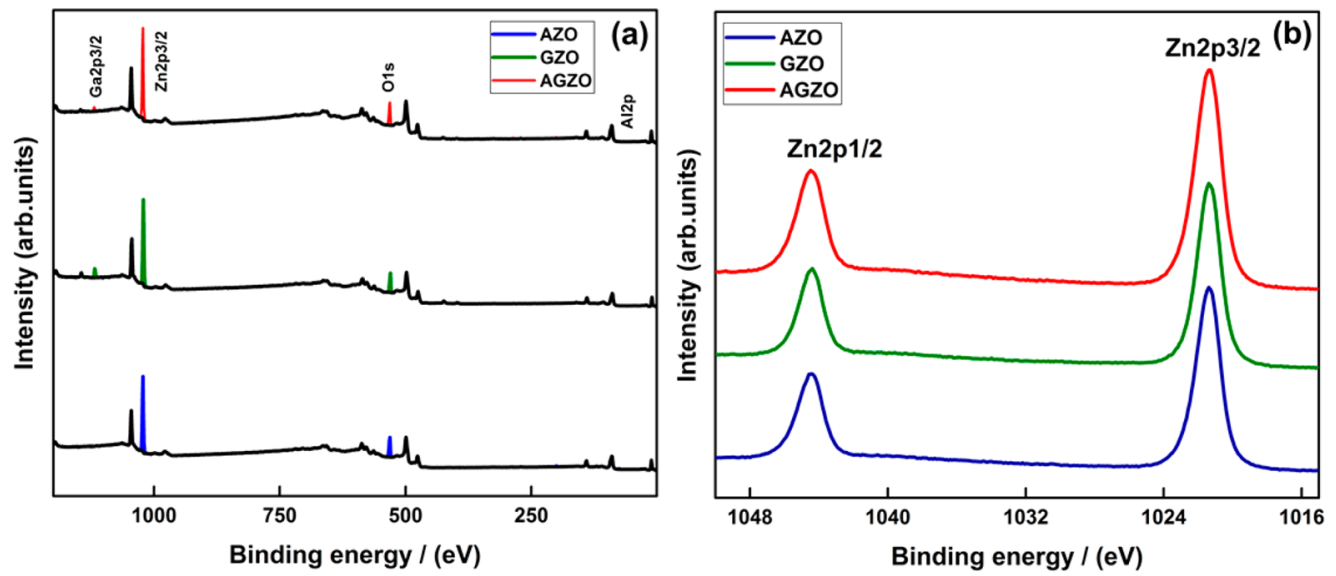

Figure 1. XPS analysis of (a) 1.5 at. \% Al-doped $\mathrm{ZnO}, 1.5$ at. \% Ga-doped $\mathrm{ZnO}$, and codoped $\mathrm{ZnO}$, and (b) Zn peaks in 1.5 at. \% (Optimum) AZO, GZO, and AGZO.
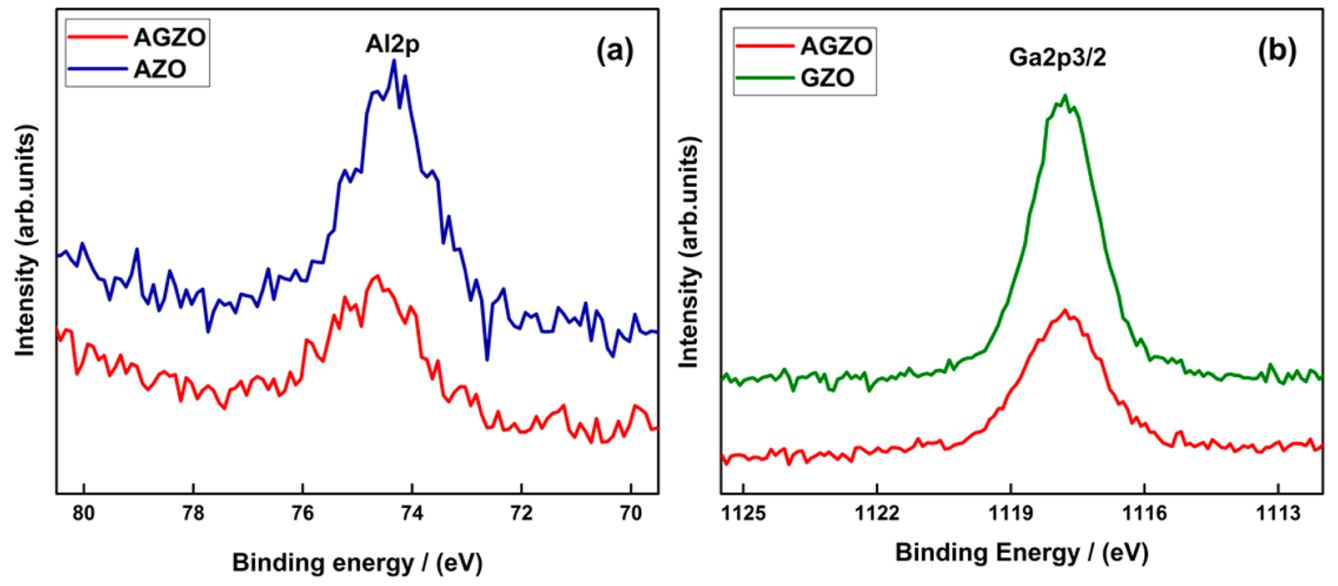

Figure 2. (a) XPS data of $\mathrm{Al} 2 \mathrm{p}$ in 1.5 at. \% AZO and AGZO; (b) XPS data of Ga 2p $\mathrm{p}_{3 / 2}$ in 1.5 at. \% GZO and AGZO.

was completed, the gas flow was maintained until the pellets cooled down to room temperature.

Thin Film Fabrication. Aerosol-assisted chemical transport (AACT) was used to fabricate thin films from nanoparticle suspensions. This method has been recently developed in our laboratory and has been used to deposit transparent conducting ITO thin films. ${ }^{26}$ For the deposition, an AGZO nanoparticle suspension was prepared by dispersing $0.2 \mathrm{~g}$ of washed powder (ca. $50 \mathrm{wt} / \mathrm{v} \%)$ in $50 \mathrm{~mL}$ of methanol (100\%, VWR Chemicals). In order to obtain a better dispersion, $0.05 \mathrm{~mL}$ of formic acid was added to the nanoparticle suspension. ${ }^{28}$ Moreover, ethyl cellulose (0.01 g) (SigmaAldrich) was added as a binding agent. ${ }^{26}$ The suspension was then sonicated for $5 \mathrm{~min}$ using a sonicator probe (S-4000, Misonix, Inc., USA). The TCO films were deposited on $1 \times 8 \mathrm{~cm}^{2}$ float glass (NSG, Pilkington, UK). Prior to the deposition, the substrates were cleaned ultrasonically with doubly distilled water, acetone, and propan-2-ol, and then stored in ethanol. In the deposition, an ultrasonically produced aerosol containing AGZO nanoparticles was directed via an $\mathrm{N}_{2}$ gas flow (BOC, UK) at an optimized flow rate of $323.27 \mathrm{~mL} \mathrm{~min}^{-1}$ toward the substrate, which was held at $400{ }^{\circ} \mathrm{C}$ (optimized temperature) in a tube furnace (MTF-10-25-130, Carbolite, UK). The deposition was carried out for $60 \mathrm{~min}$ in order to obtain a better surface coverage.

Characterization. The structural and surface analysis was carried out for the optimally doped AZO, GZO (i.e. 1.5 at. \%), and AGZO powders. The surface compositions were studied by XPS analysis. The measurements were conducted using a Thermo Scientific (model KAlpha) spectrometer for a $400 \times 400 \mu \mathrm{m}^{2}$ area. Particle size distributions of the as-synthesized powders in the reaction mixtures were monitored using a Zeta-nano from Malvern Instruments. The surface morphology of the powders was investigated using a Leo 1530 VP field emission gun scanning electron microscope (FEGSEM) at an accelerating voltage of $5 \mathrm{kV}$ and a working distance of $5 \mathrm{~mm}$. The phase and crystallinity of the TCO powders were characterized using a Bruker AXS Advance X-ray diffractometer with primary monochromatic high intensity $\mathrm{Cu} \mathrm{K} \alpha(\lambda=1.541 \AA)$ radiation and a position sensitive detector. To calculate the $c$ and $a$ lattice parameters, the Rietveld analysis technique was used. ${ }^{29,30}$ The electrical properties were measured with a four-point probe conductivity meter (Jandel, HM20, Jandel Engineering Ltd., Linslade, UK) and with a Hall effect measurement system, using the Van der Pauw method to determine the bulk resistivity of the TCOs. The pellets were subjected to an input current of $10 \mathrm{~mA}$ and a calibrated magnetic field of $0.58 \mathrm{~T}$. The transverse voltage was then measured. The measurement was repeated by reversing the direction of the magnetic field and the current. For the measurements, an ECOPIA Hall effect measurement system (HMS-3000) was used. The optical transmittance measurements of the thin films were conducted using a dual beam PerkinElmer Lambda 35 UV-vis spectrometer (PerkinElmer, Massachusetts, US) over the wavelength range $300-800 \mathrm{~nm}$.

\section{RESULTS AND DISCUSSION}

Composition, Structure, and Surface Morphology. The bonding states of $\mathrm{Al}, \mathrm{Ga}, \mathrm{Zn}$, and $\mathrm{O}$ on the surface of the optimal (1.5 at. \%) AZO, GZO, and AGZO powders were investigated by XPS surface analysis (Figure 1a). The intense peak at $1022.27 \mathrm{eV}$ was assigned to the $\mathrm{Zn} 2 \mathrm{p}_{3 / 2}$ corresponding to $\mathrm{ZnO}$ (Figure $1 \mathrm{~b}$ ). Since the peak is relatively narrow and 

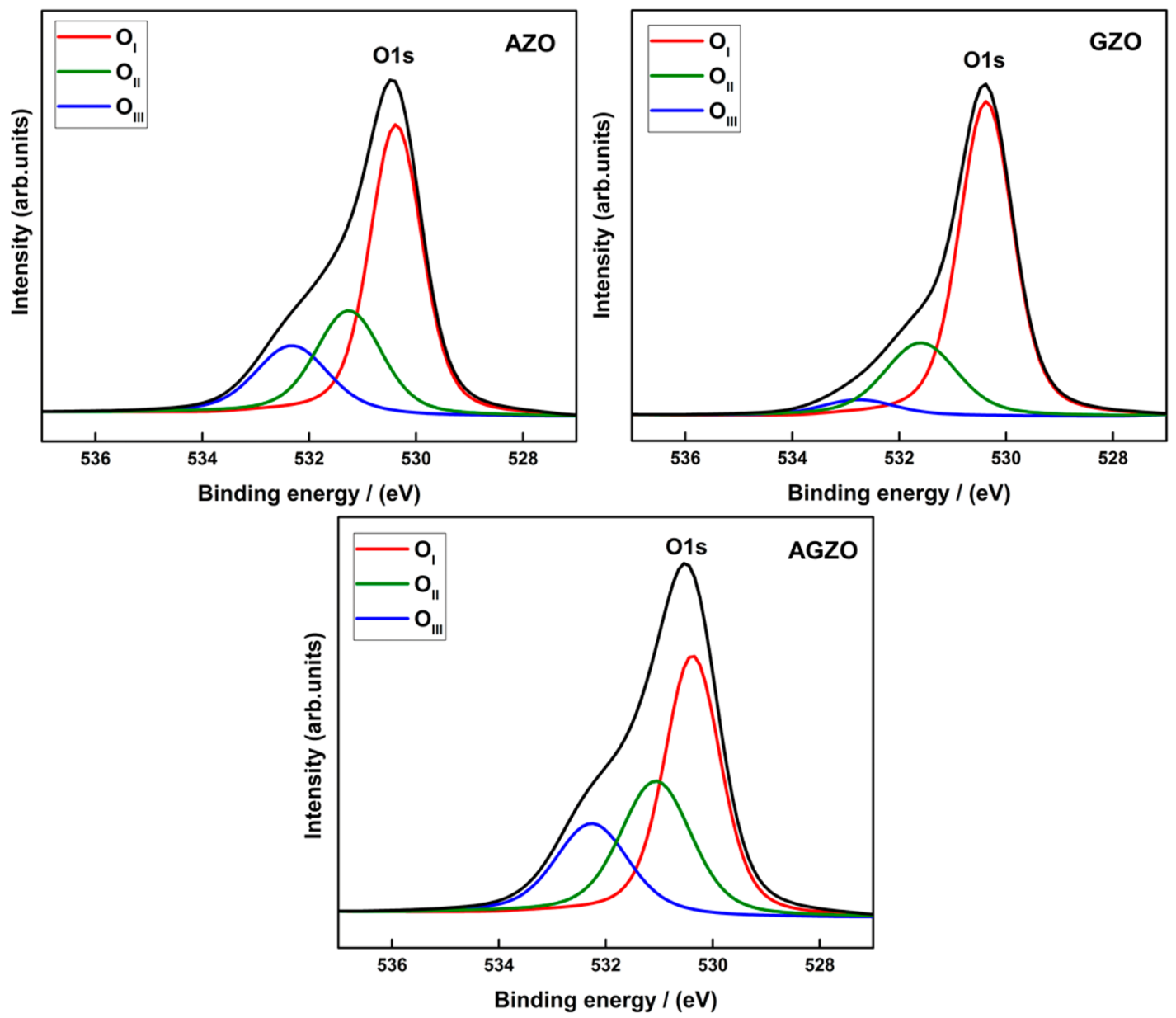

Figure 3. XPS data of $\mathrm{O} 1 \mathrm{~s}$ in optimum 1.5 at. \% $\mathrm{AZO}, 1.5$ at. \% GZO, and AGZO.

symmetric, it is believed that $\mathrm{Zn}$ predominantly exists in an oxidized state, as also confirmed by XRD. ${ }^{31,32}$ The $\mathrm{Al} 2 \mathrm{p}$ peaks located at 75.22 and $75.01 \mathrm{eV}$ in Figure $2 \mathrm{a}$ correspond to the $\mathrm{Al}-\mathrm{O}$ bond in AZO and AGZO, respectively. The characteristic peak of metallic $\mathrm{Al}(72.7 \mathrm{eV})$ was not observed in both powders. ${ }^{33}$ The XPS spectra of GZO and AGZO (Figure 2b) show peaks present at 1117.79 and $1118.71 \mathrm{eV}$, respectively, which are characteristic of $\mathrm{Ga} 2 \mathrm{p}_{3 / 2}$ in $\mathrm{Ga}-\mathrm{O} .{ }^{34}$ Metallic Ga with a binding energy of $1116.70 \mathrm{eV}$ was not observed in any of these two powder samples, confirming the presence of $\mathrm{Ga}^{3+}$ as dopant. In addition, small amounts of C (284.90-285.89 eV) and $\mathrm{Cl}(200.09 \mathrm{eV})$ were also present at impurity levels. The rest of the peaks present in the XPS spectra are auger peaks of the elements mentioned above.

The $\mathrm{O}$ 1s spectra recorded for all three powder samples (Figure 3) can be fitted to show three Gaussian binding energy components, denoted $\mathrm{O}_{\mathrm{I}}, \mathrm{O}_{\mathrm{II}}$, and $\mathrm{O}_{\mathrm{III}}$, respectively. The lower energy peak located at 530.37-531.12 eV corresponds to $\mathrm{O}^{2-}$ ions at the intrinsic sites on the wurtzite structure of the hexagonal $\mathrm{Zn}^{2+}$ (with substituted $\mathrm{Al}^{3+} / \mathrm{Ga}^{3+}$ ) array $\left(\mathrm{O}_{\mathrm{I}}\right)$. The $\mathrm{O}_{\text {II }}$ peak $(531.60-531.85 \mathrm{eV})$ is generally assigned to $\mathrm{O}^{2-}$ ions in the oxygen deficient regions. The higher energy peak $\mathrm{O}_{\text {III }}$ located at $532.76-533.00 \mathrm{eV}$ is usually attributed to the presence of loosely bound oxygen on the surface. ${ }^{35,36}$ It is noteworthy that the $\mathrm{O}_{\mathrm{I}}$ peak was found to be the dominant peak in the $\mathrm{O} 1 \mathrm{~s}$ spectra in all three doped $\mathrm{ZnO}$ powder samples, which is indeed the expected pattern.
Table S1 shows the elemental composition for the singly doped and codoped powders from the XPS measurements. As expected, the $\mathrm{Al}$ and $\mathrm{Ga}$ contents of $\mathrm{AZO}$ and GZO increase, respectively, with increasing dopant concentration in the precursor solutions. However, the dopant levels in the powder from the XPS measurements were found to be higher than expected from the initial concentrations in the precursor solutions, indicating that the dopants are more concentrated at the surface of the nanoparticles compared to the bulk.

The particle size distributions of the as-synthesized powders were measured using dynamic light scattering (DLS) in diethylene glycol (Figure 4). The measurements were carried out using suspensions that were diluted enough $(0.001 \mathrm{~g} / \mathrm{L})$ to deter particle-to-particle interactions. The average particle sizes of GZO and AZO were 100 and $250 \mathrm{~nm}$, respectively, for the optimum 1.5 at. \% doping level. The effect of precursor concentration on the average particle size distribution was investigated for the optimized AGZO powder, with different concentrations of precursor varying from 0.025 to $0.1 \mathrm{~mol}$. $\mathrm{dm}^{-3}$. It was observed that reducing the concentration results in a smaller average particle size distribution. The lowest average particle size $(\sim 85 \mathrm{~nm})$ was detected for the suspension with $0.025 \mathrm{~mol} \cdot \mathrm{dm}^{-3}$ concentration, which was stable as a colloid for more than a month. Suspensions of conducting materials with this level of stability could be used in developing TCO ink formulations for inkjet printing, which is beyond the scope of the present work. 

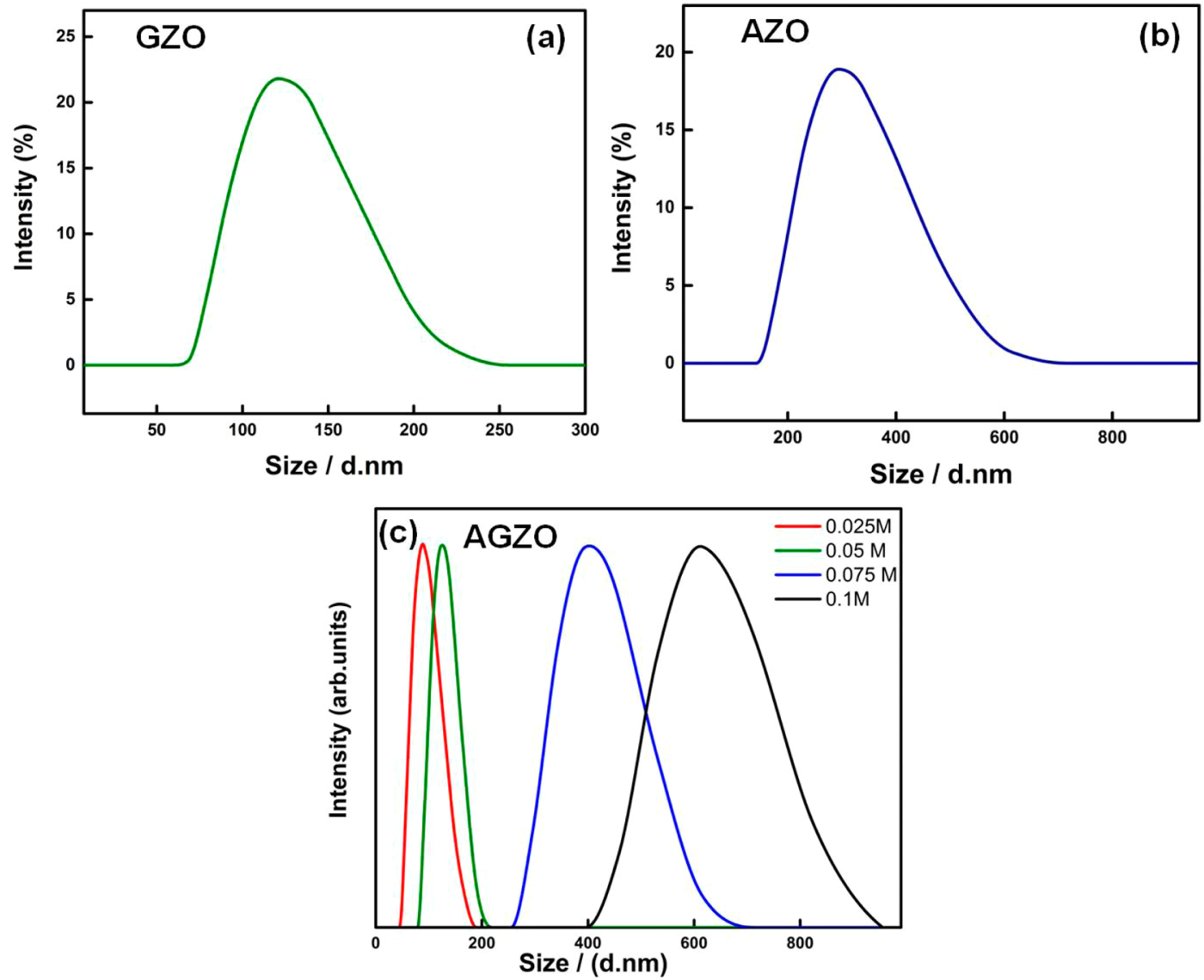

Figure 4. Particle size distribution of as-synthesized powders in diethylene glycol: (a) 1.5 at. \% GZO; (b) 1.5 at. \% AZO; (c) AGZO with different precursor concentrations.

Figure 5 shows the morphology and structural features of assynthesized optimal AZO, GZO, and AGZO powders. Both singly doped and codoped powders exhibited a broad size distribution with particles around (100-200) nm. The FEGSEM images of powders clearly show polycrystalline clusters of nanoparticles which are mostly spherical. Formation of these agglomerated spherical clusters is most likely due to the high surface energy of individual nanoparticles. ${ }^{37}$

Figure 6 shows the surface morphology of AGZO pellets subjected to $90 \mathrm{~s}$ of microwave sintering and $3 \mathrm{~h}$ of radiant annealing at $600{ }^{\circ} \mathrm{C}$. No cracks were seen through the pellets surfaces. However, cavities are visible between the grains in both pellets after heat treatment. A color change in the pellets (Figure 7) was observed after heat treatment, implying a shift from lower density to higher density. ${ }^{38}$

Figure 8 shows the $\mathrm{X}$-ray diffraction spectra of microwavesynthesized pure $\mathrm{ZnO}$, and the best singly doped and codoped powders, which gave the lowest resistivity values. The powder samples exhibited only the polycrystalline $\mathrm{ZnO}$ reflections, with a preferred orientation of (101), indicating a preferential orientation of the crystals along the $a$ and $c$ axes. ${ }^{39,24,25}$ All doped and undoped powders crystallized in the wurtzite structure. $^{40}$ No other phases were detected in the XRD data. The high crystallinity of the microwave-synthesized powders was implied by the sharpness and the relatively high intensity of the reflections in the XRD patterns. It is well-known that volumetric heating by microwaves produces materials with a greater level of crystallinity than those produced by many other conventional synthesis methods. ${ }^{41,42}$ In order to compare the
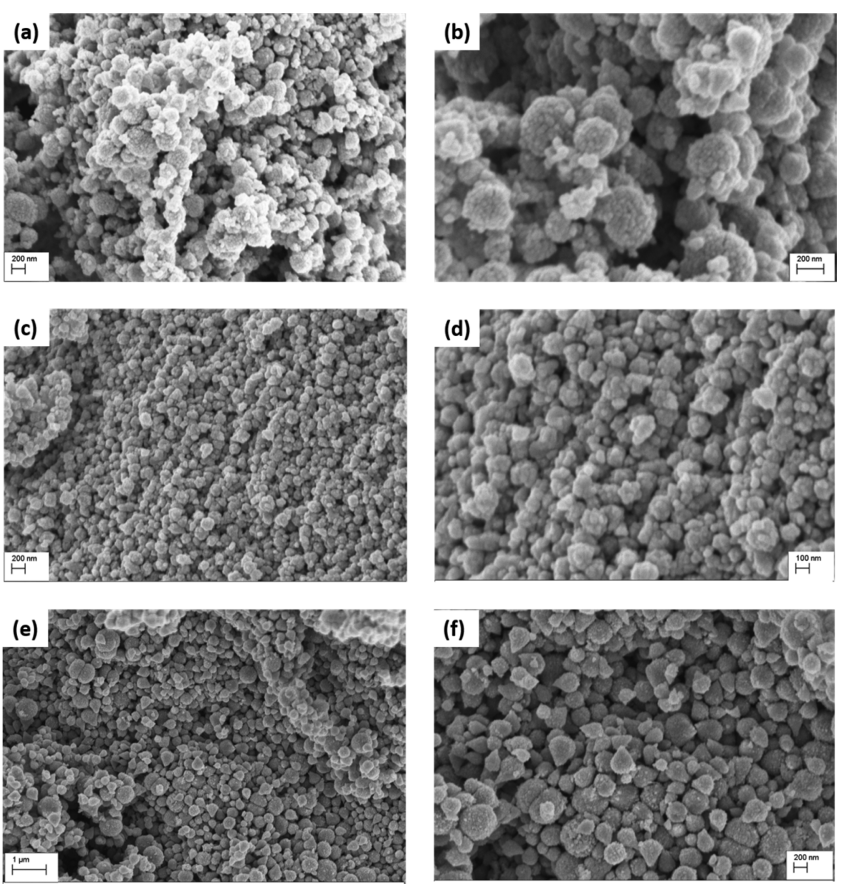

Figure 5. FEG-SEM images of as-synthesized powders of ( $a$ and $b$ ) 1.5 at. \% Al-doped $\mathrm{ZnO}$, (c and d) 1.5 at. \% Ga-doped $\mathrm{ZnO}$, and (e and f) $\mathrm{Al}$, Ga codoped $\mathrm{ZnO}$.

crystallinity and the average crystallite sizes, full width at halfmaximum (fwhm) values were obtained for the (101) 

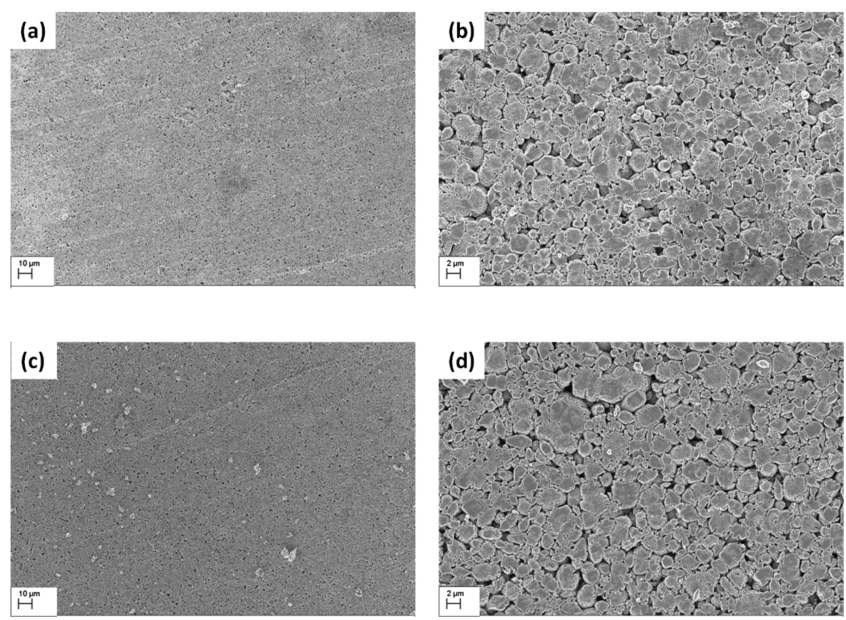

Figure 6. FEG-SEM images of AGZO pellets: ( $a$ and $b$ ) microwave postsynthesis heat treated; ( $c$ and $d$ ) conventionally postsynthesis heat treated.
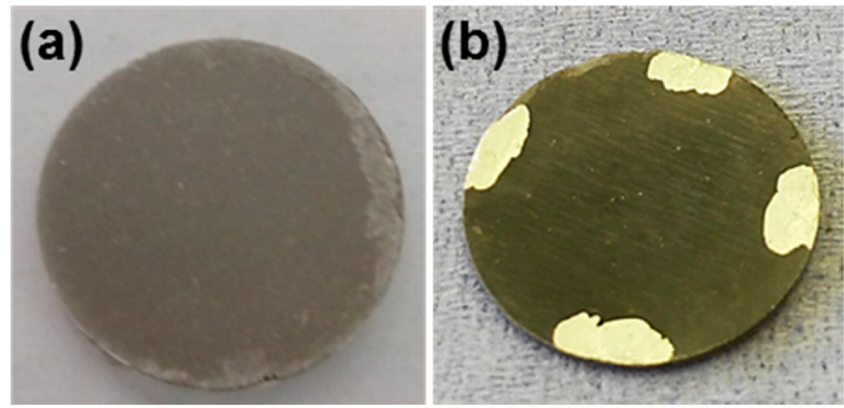

Figure 7. Color change in AGZO pellets (a) before annealing and (b) after annealing.

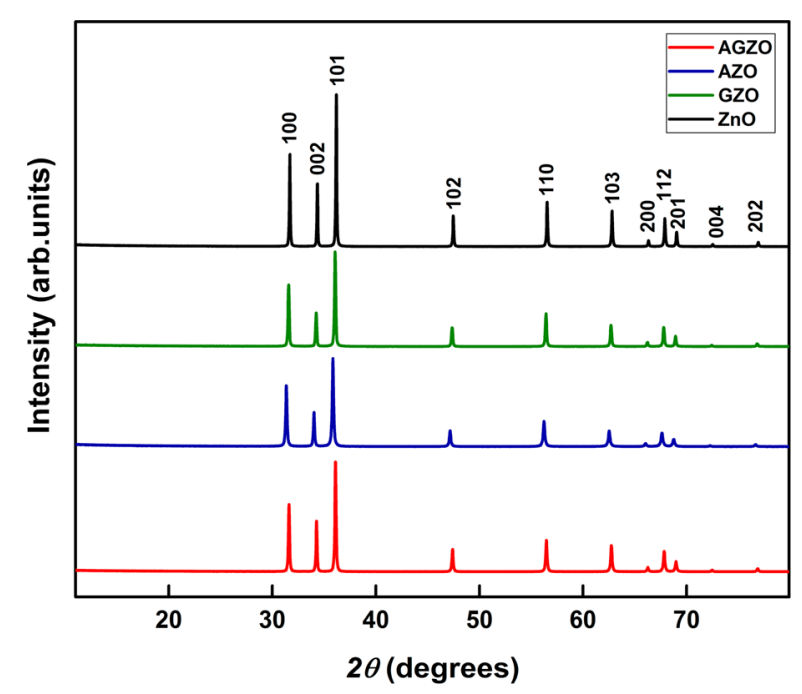

Figure 8. $\mathrm{XRD}$ patterns of as-synthesized $\mathrm{ZnO}$, and best singly doped and codoped powders. dominant reflection planes for the best AZO, GZO, and AGZO powders, which were then used to calculate the crystallite size using the Scherrer equation. ${ }^{43}$ Furthermore, the unit cell volumes were calculated using GSAS and EXPGUI, and they are shown in Table 1.

Highly crystallized polycrystalline materials with larger grains show strong XRD reflections and a narrow fwhm. ${ }^{44}$ AGZO and GZO showed similar fwhm values and crystallite sizes. The higher fwhm and the lower crystallite size in the AZO powder imply reduced crystallinity in AZO compared to GZO and AGZO. The wurtzite structure of $\mathrm{ZnO}$ has a hexagonal unit cell with two lattice parameters, $a$ and $c{ }^{45} \mathrm{ZnO}$ lattice parameters $(a=3.2520 \AA, c=5.2101 \AA)$ and their ratio $(c / a=1.6021)$ are similar to the values for the hexagonal close-packed (hcp) crystal structure. A variation in the lattice parameters and the unit cell volumes is observed after doping, due to the difference in the ionic radii of the dopants compared to that of $\mathrm{Zn}^{2+}$, as explained in detail later.

Electrical Properties of Pellets. The resistivity $(\rho)$, Hall mobility $(\mu)$, and carrier concentration $(n)$ values of microwave annealed and conventional radiant annealed, singly doped pellets are summarized in Figures 9 and 10. The electrical properties of the as-synthesized powder pellets could not be assessed due to the low robustness of the pelleted samples. Therefore, postsynthesis heat treatment was carried out to densify the pellets, and improve their interparticle connections and mechanical stability. ${ }^{20}$ The resistivity of the pellets decreased upon increasing the doping content up to a certain amount, but further addition of dopants gave rise to a higher resistivity. At the dopant content of 1.5 at. \%, both AZO and GZO pellets gave the lowest resistivity of $4.4 \times 10^{-3}$ and $4.3 \times$ $10^{-3} \Omega \cdot \mathrm{cm}$, respectively, after the microwave postsynthesis heat treatment. Interestingly, the resistivity values of the pellets obtained from both heat treatment methods were comparable.

An increase in the carrier density from 0.5 at. \% to 2.5 at. \% dopant content of singly doped pellets was observed after the microwave heat treatment. This phenomenon is understood as an effect of increasing the amount of free carriers by substitutional or interstitial incorporation of $\mathrm{Al}^{3+}$ and $\mathrm{Ga}^{3+}$ in the $\mathrm{ZnO}$ structure. ${ }^{46}$ The mobility of the carriers in highly doped pellets was seen to decrease, coinciding with lower conductivities. This could be a result of carrier-carrier scattering and ionized impurity scattering, which could potentially take place at higher carrier densities $\geq 10^{19} \mathrm{~cm}^{3} . .47,48$

For conventional radiant annealed AZO and GZO samples, the carrier density peaks at 1.5 at. \%, then decrease upon further doping. This effect is most likely due to the difference in heating time required for the two annealing techniques used in this work. Microwave annealing was carried out for $90 \mathrm{~s}$ in the reducing atmosphere of $5 \% \mathrm{H}_{2} / \mathrm{N}_{2}\left(\sim \mathrm{O}_{2} 5 \mathrm{ppm}\right)$, while the conventional heat treatment was carried out for much longer $(3$ h). During the longer conventional heat treatment, there is a greater chance of forming oxygen interstitials, by diffusion of trapped $\mathrm{O}^{2-}$ species (usually found at the surface of grain

Table 1. Summary of Structural Properties of the Best Al- and Ga-Doped As-Synthesised Powders

\begin{tabular}{|c|c|c|c|c|c|c|}
\hline Sample & fwhm (deg) & $a(\AA)$ & $c(\AA)$ & $c / a$ & $V\left(\AA^{3}\right)$ & $d(\mathrm{~nm})$ \\
\hline AGZO & 0.1500 & $3.25244(9)$ & $5.2099(2)$ & 1.6018 & $47.723(3)$ & 55.6530 \\
\hline 1.5 at. $\%$ GZO & 0.1520 & $3.2521(9)$ & $5.209(1)$ & 1.6017 & $47.71(4)$ & 54.8878 \\
\hline 1.5 at. $\%$ AZO & 0.1980 & $3.251(1)$ & $5.208(1)$ & 1.6019 & $47.68(4)$ & 42.1738 \\
\hline $\mathrm{ZnO}$ & 0.1320 & $3.2520(8)$ & $5.210(1)$ & 1.6021 & $47.72(3)$ & 63.2471 \\
\hline
\end{tabular}



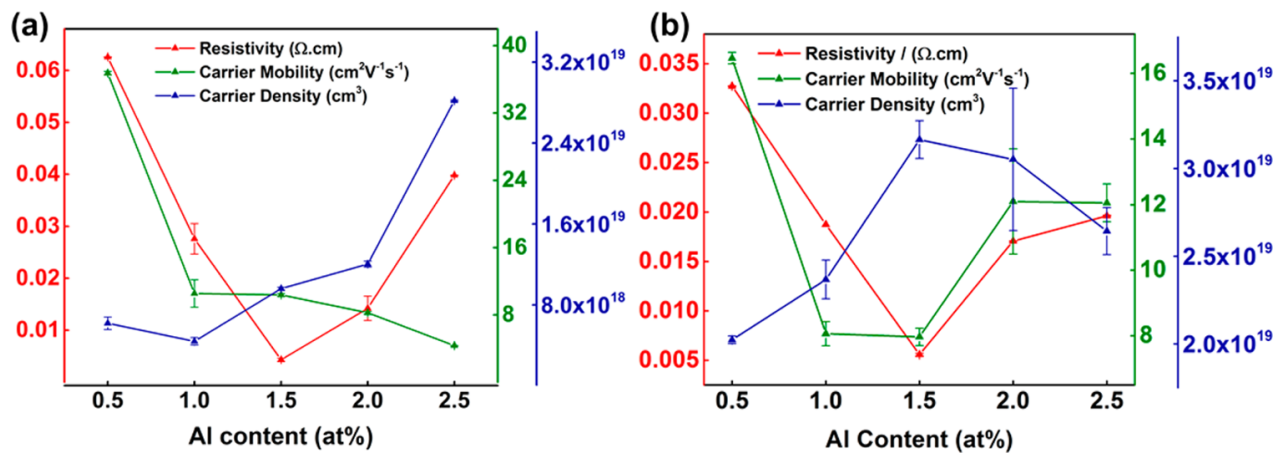

Figure 9. Electrical properties of (a) microwave annealed and (b) radiant annealed AZO pellets.
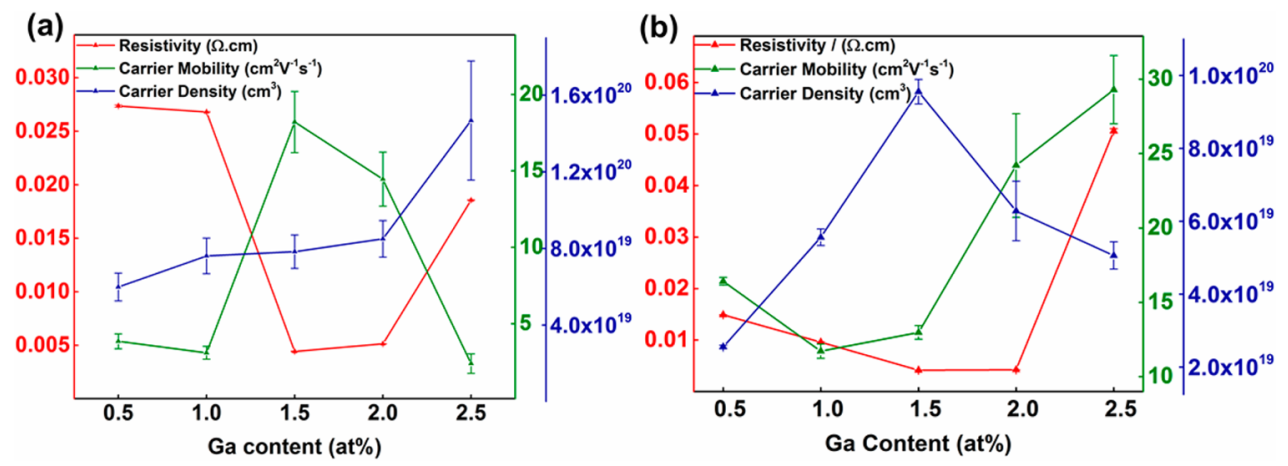

Figure 10. Electrical properties of (a) microwave annealed and (b) radiant annealed GZO pellets.

boundaries) into the crystal lattice, which may unfavorably affect the carrier density. ${ }^{49,36,50}$ At the same time, the larger crystallite size formed by the longer heating time leads to a decrease in the grain boundary scattering and an improvement in the charge carrier mobility values. ${ }^{46,51}$

The effective doping of metal ions into $\mathrm{ZnO}$ plays a key role in improving the electrical properties of doped $\mathrm{ZnO}$ materials. The dopant substitution into the $\mathrm{ZnO}$ structure can be affected by the ionic radii of the dopants $\left(r\left(\mathrm{Zn}^{2+}\right)=0.74 \AA, r\left(\mathrm{Al}^{3+}\right)=\right.$ $0.54 \AA, r\left(\mathrm{Ga}^{3+}\right)=0.62 \AA$ ) and the Madelung energy. ${ }^{52,53}$ As the ionic radii of $\mathrm{Al}^{3+}$ and $\mathrm{Ga}^{3+}$ are both smaller than that of $\mathrm{Zn}^{2+}$, the $\mathrm{Al}-\mathrm{O}(1.81 \AA)$ and $\mathrm{Ga}-\mathrm{O}(1.90 \AA)$ covalent bonds are shorter than the $\mathrm{Zn}-\mathrm{O}(2.00 \AA)$ covalent bonds in the powders. ${ }^{54}$ Therefore, increasing the dopant substitution can produce more crystal strain within the $\mathrm{ZnO}$ lattice, boosting the Madelung energy, making the structure unstable. Thus, a "saturation" point exists, beyond which the addition of further dopants, via the increase of the dopant concentration, could have a detrimental effect on the crystallinity. ${ }^{55}$ Furthermore, due to the poor solubility of dopants in the $\mathrm{ZnO}$ structure at higher dopant levels, it is possible that segregation of a small secondary phase of nonconductive $\mathrm{Al}$ or $\mathrm{Ga}$ oxide is formed at the grain boundaries (of the respective doped $\mathrm{ZnO}$ material), which may lead to the increase of resistivity seen for concentrations above 1.5 at. \% (Figures 9 and 10). ${ }^{56}$

In the case of AGZO, it is possible that the simultaneous introduction of both dopants in the lattice structure may lead to a compensation effect, whereby the difference in size of the two dopants helps to reduce some of the crystal strain, in turn allowing greater dopant solubility in the $\mathrm{ZnO}$ structure. ${ }^{57}$ This improved doping of $\mathrm{Al}$ and $\mathrm{Ga}$ into the $\mathrm{ZnO}$ structure could reduce the formation of interstitials, nonconductive oxide phases, and the accumulation of dopant elements, enhancing the electrical properties in AGZO. Correspondingly, the codoping leads to a more pronounced drop in the resistivity $\left(5.6 \times 10^{-4} \Omega \cdot \mathrm{cm}\right)$ compared to the single doped powders (Table 2).

Table 2. Electrical Properties of AGZO Pellets and Thin Films

\begin{tabular}{lcccc} 
Pellets & $\boldsymbol{\rho}(\boldsymbol{\Omega} \cdot \mathrm{cm})$ & $\boldsymbol{\mu}\left(\mathrm{cm}^{2} \cdot \mathbf{V}^{-1} \cdot \mathbf{s}^{-1}\right)$ & $\boldsymbol{N}\left(\mathrm{cm}^{3}\right)$ \\
& $\begin{array}{c}\text { Microwave } \\
\text { AGZO } \\
\text { Conventional } \\
\text { AGZO }\end{array}$ & $5.6 \times 10^{-4}$ & 8.32 & $8 \times 10^{20}$ \\
$\begin{array}{c}\text { Thin } \\
\text { films }\end{array}$ & $\begin{array}{c}\text { AACT AGZO } \\
\text { AG1 }\end{array}$ & $5.7 \times 10^{-4}$ & 12.74 & $6 \times 10^{20}$ \\
\hline
\end{tabular}

Table 2 summarizes the electrical properties of pelleted microwave-synthesized AGZO powder samples after the postsynthesis heat treatment. The lowest resistivity values of $5.6 \times 10^{-4} \Omega \cdot \mathrm{cm}$ and $6.1 \times 10^{-4} \Omega \cdot \mathrm{cm}$ were observed for the pellets annealed by microwave and radiant annealing methods, respectively. As mentioned in the previous discussion, the reduced resistivity in AGZO is possibly due to the exceptional charge carrier properties achieved by the effective doping, with a minimal effect on $\mathrm{ZnO}$ crystalline lattice structure, as evident by the XPS and XRD analysis.

Thin Film Fabrication. In order to establish the practicality of using the conducting nanoparticles as TCO coatings, thin films were fabricated by the AACT technique. The surface morphological images of the AACT-deposited AGZO films are illustrated in Figure 11. The images indicated that the deposited films showed a good surface coverage with fused AGZO nanoparticles deposited at $400{ }^{\circ} \mathrm{C}$. The best conductivity was achieved for the thin film coatings fabricated using codoped AGZO powders with the optimal doping levels of 1.5 at. \% for $\mathrm{Al}$ and Ga. Electrical properties obtained by the Hall effect 


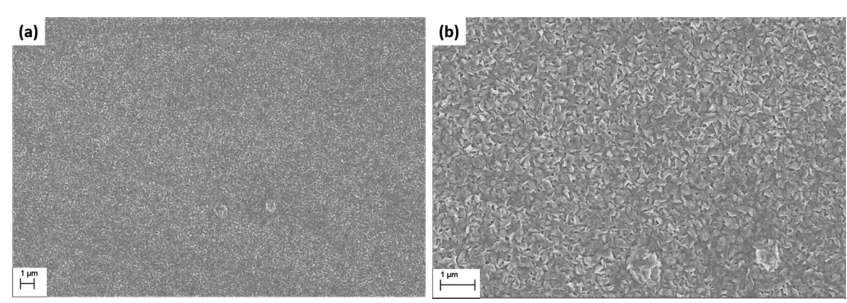

Figure 11. FEG-SEM images of AGZO thin film with (a) $10 \mathrm{~K} \times$ and (b) $20 \mathrm{~K} \times$ magnifications.

measurements are presented in Table 2 . A film resistivity of 5.7 $\times 10^{-3} \Omega \cdot \mathrm{cm}$ was observed (for the film thickness of $500 \mathrm{~nm}$ ) with a transparency of $90 \%$ in the visible region of the spectrum as shown in Figure 12. As discussed previously, the conductivity

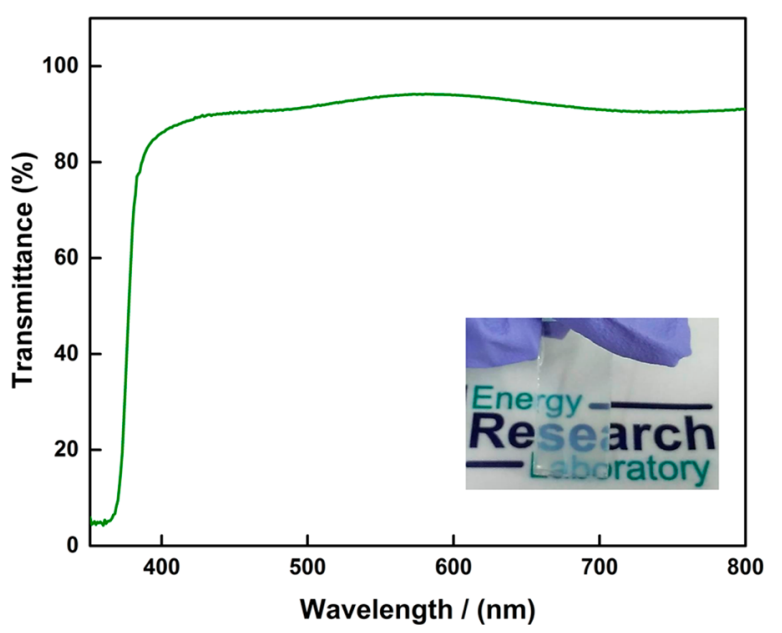

Figure 12. Optical transmission spectrum of AGZO thin film deposited by AACT from a methanolic suspension. The inset is a photograph of the glass sample showing the optical transmission.

is a concerted effect between the carrier concentration and the Hall mobility of donors. Hence, the variation in the resistivity of the thin film compared to the AGZO pellets is possibly due to the drop in the carrier density. A similar behavior has been observed by other groups for the sputter-coated films at temperatures above $250{ }^{\circ} \mathrm{C} .{ }^{58,59}$ According to their reports, it is possible to lose zinc species via re-evaporation or dopant migration to the grain boundaries. Thus, it forms small regions of nonconducting oxides rather than remaining as a dopant, which conversely act as scattering centers. Both influence the carrier density unfavorably, causing an increase in the resistivity. Furthermore, this could also create defects in the crystal structure, adversely affecting the crystallinity. We believe that a similar phenomenon is causing the drop in the carrier density, hence the increase in the resistivity in the thin film compared to that in the AGZO pellet. XRD analysis shows that the $\mathrm{ZnO}$ thin film grows in the wurtzite phase, preferentially along the $c$ axis with a prominent peak from the (002) plane (Figure S3). ${ }^{58}$ No impurity phases were detected in the XRD pattern of the thin films. It was also noticed that the intensity of some of the $\mathrm{ZnO}$ reflections decreased after the thin film fabrication, indicating an alteration in the crystallinity and further suggesting that higher deposition temperature could be the cause of the reduced carrier density. The film adherence was assessed by employing the standard scotch tape test. Successful test results confirmed that the thin film is mechanically stable and well adhered to the glass substrate (Figure S4).

\section{CONCLUSIONS}

Al-doped $\mathrm{ZnO}$ (AZO), Ga-doped $\mathrm{ZnO}$ (GZO), and Al, Ga codoped $\mathrm{ZnO}$ (AGZO) materials were successfully synthesized by a single-step microwave-assisted method. Studies conducted on all three pelleted powder samples indicate that codoping leads to a more pronounced drop in the resistivity $\left(5.6 \times 10^{-4}\right.$ $\Omega \cdot \mathrm{cm}$ ) compared to the singly doped powders, which we propose is due to the exceptional charge carrier properties achieved by effective doping, with a minimal effect on the $\mathrm{ZnO}$ crystalline lattice structure. The electrical properties of all samples illustrate that comparable resistivity values, for both singly doped and codoped $\mathrm{ZnO}$ pellets, can be obtained via the energy efficient, rapid (i.e., $90 \mathrm{~s}$ ) microwave postsynthesis heat treatment rather than the long (i.e., $3 \mathrm{~h}$ ) radiant annealing method. This could bring significant scientific, economic, and environmental benefits for industrial scale-up by saving costs and time. The highly stable nature of the microwavesynthesized nanoparticle suspensions means that they could be useful in preparation of ink formulations for inkjet printing. As a proof of concept, transparent conducting thin films were fabricated via a simple aerosol-assisted deposition technique using AGZO nanoparticles. The films exhibited a visible transmittance of $90 \%$ and a resistivity of $5.7 \times 10^{-3} \Omega \cdot \mathrm{cm}$. This study shows that there is significant potential to develop microwave-synthesized $\mathrm{Al}, \mathrm{Ga}$ codoped $\mathrm{ZnO}$ as a promising alternative transparent conducting material, which is suitable to be used for both physical and solution processed thin film fabrication to make TCO coatings benefiting many applications where alternative TCO coatings are in significant demand.

\section{ASSOCIATED CONTENT}

\section{Supporting Information}

The Supporting Information is available free of charge on the ACS Publications website at DOI: 10.1021/acssuschemeng.7b00263.

Details of temperature, pressure, and microwave power profiles for the microwave synthesis; step-by-step scheme of microwave synthesis of doped $\mathrm{ZnO}$ powder; the XPS data of the singly doped and codoped $\mathrm{ZnO}$ powders; $\mathrm{XRD}$ patterns of as-synthesized $\mathrm{ZnO}$, and best singly doped and codoped powders; and images of the scotch tape test for the AGZO thin film deposited by AACT. (PDF)

\section{AUTHOR INFORMATION}

\section{Corresponding Author}

*E-mail: u.wijayantha@lboro.ac.uk.

ORCID

K. G. U. Wijayantha: 0000-0003-0258-2385

C. J. Carmalt: 0000-0003-1788-6971

Notes

The authors declare no competing financial interest.

\section{ACKNOWLEDGMENTS}

This research was funded by the UK Engineering and Physical Sciences Research Council (EPSRC) under grant number EP/ L017709/1. The authors also thank UCL for a studentship (DOP). The authors gratefully acknowledge the support of the 
industrial collaborators, especially Malvern Instruments Ltd, Sun Chemical Ltd, and NSG. The assistance received from all members of the Energy Research Laboratory in the Department of Chemistry, Loughborough University, is also acknowledged. The authors acknowledge use of facilities within the Loughborough Materials Characterisation Centre (LMCC) and CREST at Loughborough University. We would also like to thank Patricia Cropper for her assistance in obtaining XPS measurements.

\section{REFERENCES}

(1) Liu, Y.; Li, Y.; Zeng, H. ZnO-Based Transparent Conductive Thin Films: Doping, Performance, and Processing. J. Nanomater. 2013, 2013, 1-9.

(2) Kaur, G.; Mitra, A.; Yadav, K. L. Pulsed laser deposited Al-doped $\mathrm{ZnO}$ thin films for optical applications. Prog. Nat. Sci. 2015, 25 (1), $12-21$.

(3) Howard, D. P.; Marchand, P.; Johnson, I. D.; Carmalt, C. J.; Parkin, I. P.; Darr, J. A.; Edwards, P. P.; Porch, A.; Jones, M. O.; Morgan, D. V.; et al. Conducting $\mathrm{Al}$ and Ga-doped zinc oxides; rapid optimization and scale-up. J. Mater. Chem. A 2016, 4 (33), 1277412780 .

(4) Ghanizadeh, S.; Peiris, T. A. N.; Jayathilake, D. S. Y.; Hutt, D. A.; Wijayantha, K. G. U.; Southee, D. J.; Conway, P. P.; Marchand, P.; Darr, J. A.; Parkin, I. P.; et al. Dispersion and microwave processing of nano-sized ITO powder for the fabrication of transparent conductive oxides. Ceram. Int. 2016, 42 (16), 18296-18302.

(5) Xiu, S.; Wei, T.; Yang, Y.; Zhang, T.; Li, J.; Song, W. Preparation of AZO nanoparticles, ceramic targets and thin films by a Coprecipitaition method. J. Wuhan Univ. Technol., Mater. Sci. Ed. 2015, 30 (6), 1134-1139.

(6) Lv, J.; Li, C. Evidences of VO, VZn, and Oi defects as the green luminescence origins in ZnO. Appl. Phys. Lett. 2013, 103 (23), 232114.

(7) Zhang, Z.; Look, D. C.; Schifano, R.; Johansen, K. M.; Svensson, B. G.; Brillson, L. J.; C, L. D.; Pearton, S. J.; N, D. P. I. L. H. Y. W.; S, T.; Look D C, H. J. W.; S, J. R.; G, J. A.; V. de, W. C.; et al. Process dependence of $\mathrm{H}$ passivation and doping in $\mathrm{H}$-implanted $\mathrm{ZnO}$. J. Phys. D: Appl. Phys. 2013, 46 (5), 055107.

(8) Wang, Y. G.; Lau, S. P.; Lee, H. W.; Yu, S. F.; Tay, B. K.; Zhang, X. H.; Hng, H. H. Photoluminescence study of $\mathrm{ZnO}$ films prepared by thermal oxidation of $\mathrm{Zn}$ metallic films in air. J. Appl. Phys. 2003, 94 (1), 354.

(9) Hussain, S.; Khan, Y.; Khranovskyy, V.; Muhammad, R.; Yakimova, R. Effect of oxygen content on the structural and optical properties of $\mathrm{ZnO}$ films grown by atmospheric pressure MOCVD. Prog. Nat. Sci. 2013, 23 (1), 44-50.

(10) Rao, T. P.; Raj, S. G.; Kumar, M. C. S. Effect of Annealing Atmosphere on Structural and Optical Properties of Nd:ZnO Thin Films. Procedia Mater. Sci. 2014, 6, 1631-1638.

(11) Zhang, Z.; Look, D. C.; Schifano, R.; Johansen, K. M.; Svensson, B. G.; Brillson, L. J. Process dependence of $\mathrm{H}$ passivation and doping in H-implanted ZnO. J. Phys. D: Appl. Phys. 2013, 46 (5), 055107.

(12) Janotti, A.; Walle, C. G. Van De. Native point defects in $\mathrm{ZnO}$.

Phys. Rev. B: Condens. Matter Mater. Phys. 2007, 76, 165202-1 - 22.

(13) Look, D. C.; Farlow, G. C.; Reunchan, P.; Limpijumnong, S.; Zhang, S. B.; Nordlund, K. Evidence for Native-Defect Donors in $\mathrm{n}$ -Type ZnO. Phys. Rev. Lett. 2005, 95 (22), 225502.

(14) Ogata, K.; Sakurai, K.; Fujita, S.; Fujita, S.; Matsushige, K. Effects of thermal annealing of $\mathrm{ZnO}$ layers grown by MBE. J. Cryst. Growth 2000, 214, 312-315.

(15) Cho, J.; Nah, J.; Oh, M.-S.; Song, J.-H.; Yoon, K.-H.; Jung, H.-J.; Choi, W.-K. Enhancement of Photoluminescence and Electrical Properties of Ga-Doped ZnO Thin Film Grown on $\alpha$-Al2O3(0001) Single-Crystal Substrate by rf Magnetron Sputtering through Rapid Thermal Annealing. Jpn. J. Appl. Phys. 2001, 40, L1040-L1043.

(16) Shu-wen, X. A Study of Annealing Time Effects on the Properties of Al:ZnO. Phys. Procedia 2012, 25, 345-349.
(17) Kim, J.; Yun, J.-H.; Park, Y. C.; Anderson, W. A. Transparent and crystalline $\mathrm{Al}$-doped $\mathrm{ZnO}$ film-embedded heterojunction $\mathrm{Si}$ solar cell. Mater. Lett. 2012, 75, 99-101.

(18) Minami, T. Transparent conducting oxide semiconductors for transparent electrodes. Semicond. Sci. Technol. 2005, 20 (4), S35-S44.

(19) Nomoto, J.; Konagai, M.; Miyata, T.; Minami, T. Resistivity characteristics of transparent conducting impurity-doped $\mathrm{ZnO}$ films for use in oxidizing environments at high temperatures. J. Vac. Sci. Technol., A 2010, 28 (4), 861.

(20) Wu, R.; Zhang, W.; Zhang, H.; Song, D.; Ma, Q.; Liu, J.; Ma, X.; Zhang, L.; Zhang, L.; Song, H. Investigation of aluminum and gallium co-doped $\mathrm{ZnO}$ powders and their effects on the properties of targets. Mater. Sci. Semicond. Process. 2014, 19, 24-31.

(21) Howard, D. P.; Marchand, P.; Mcca, L.; Carmalt, C. J.; Parkin, I. P.; Darr, J. A. High-Throughput Continuous Hydrothermal Synthesis of Transparent Conducting Aluminum and Gallium Co-doped Zinc Oxides. ACS Comb. Sci.. 2017, 19, 23910.1021/acscombsci.6b00118

(22) Peiris, N. Microwave-assisted processing of solid materials for sustainable energy related electronic and optoelectronic applications. Loughborough University, 2014.

(23) Hammarberg, E.; Prodi-Schwab, A.; Feldmann, C. Microwaveassisted synthesis of indium tin oxide nanocrystals in polyol media and transparent, conductive layers thereof. Thin Solid Films 2008, 516 (21), 7437-7442.

(24) Hammarberg, E.; Prodi-Schwab, A.; Feldmann, C. Microwaveassisted polyol synthesis of aluminium- and indium-doped $\mathrm{ZnO}$ nanocrystals. J. Colloid Interface Sci. 2009, 334 (1), 29-36.

(25) Luo, L.; Rossell, M. D.; Xie, D.; Erni, R.; Niederberger, M. Microwave-Assisted Nonaqueous Sol-Gel Synthesis: From Al:ZnO Nanoparticles to Transparent Conducting Films. ACS Sustainable Chem. Eng. 2013, 1 (1), 152-160.

(26) Nirmal Peiris, T. A.; Ghanizadeh, S.; Jayathilake, D. S. Y.; Hutt, D. A.; Wijayantha, K. G. U.; Conway, P. P.; Southee, D. J.; Parkin, I. P.; Marchand, P.; Darr, J. A.; et al. Aerosol-assisted fabrication of tindoped indium oxide ceramic thin films from nanoparticle suspensions. J. Mater. Chem. C 2016, 4 (24), 5739-5746.

(27) Das, S. D. Prospects of Microwave Heating in Silicon Solar Cell Fabrication - A Review. IOSR J. Electr. Electron. Eng. 2013, 6 (3), 2838.

(28) Grubbs, R. B. Roles of Polymer Ligands in Nanoparticle Stabilization. Polym. Rev. 2007, 47 (2), 197-215.

(29) Larson, A. C.; Von Dreele, R. B. General Structure Analysis System (GSAS); 2000.

(30) Toby, B. H. EXPGUI, a graphical user interface for GSAS. J. Appl. Crystallogr. 2001, 34, 210-213.

(31) Wang, J.; Wang, Y.; Xie, S.; Qiao, M.; Li, H.; Fan, K. Partial hydrogenation of benzene to cyclohexene on a $\mathrm{Ru}-\mathrm{Zn} / \mathrm{m}-\mathrm{ZrO} 2$ nanocomposite catalyst. Appl. Catal., A 2004, 272 (1), 29-36.

(32) Islam, M. N.; Ghosh, T. B.; Chopra, K. L.; Acharya, H. N. XPS and X-ray diffraction studies of aluminum-doped zinc oxide transparent conducting films. Thin Solid Films 1996, 280 (1-2), 20-25.

(33) Kim, J.-P.; Lee, S.-A.; Bae, J. S.; Park, S.-K.; Choi, U.-C.; Cho, C.-R. Electric properties and surface characterization of transparent Aldoped $\mathrm{ZnO}$ thin films prepared by pulsed laser deposition. Thin Solid Films 2008, 516 (16), 5223-5226.

(34) Prasada Rao, T.; Santhosh Kumar, M. C. Resistivity Stability of Ga Doped ZnO Thin Films with Heat Treatment in Air and Oxygen Atmospheres. J. Cryst. Process Technol. 2012, 02 (02), 72-79.

(35) Chen, M.; Wang, X.; Yu, Y. H.; Pei, Z. L.; Bai, X. D.; Sun, C.; Huang, R. F.; Wen, L. S. X-ray photoelectron spectroscopy and auger electron spectroscopy studies of $\mathrm{Al}$-doped $\mathrm{ZnO}$ films. Appl. Surf. Sci. 2000, 158 (1), 134-140.

(36) Hai-Bo, F.; Shao-Yan, Y.; Pan-Feng, Z.; Hong-Yuan, W.; XiangLin, L.; Chun-Mei, J.; Qin-Sheng, Z.; Yong-Hai, C.; Zhan-Guo, W. Investigation of Oxygen Vacancy and Interstitial Oxygen Defects in $\mathrm{ZnO}$ Films by Photoluminescence and X-Ray Photoelectron Spectroscopy. Chin. Phys. Lett. 2007, 24 (7), 2108-2111.

(37) Shen, X. S.; Wang, G. Z.; Hong, X.; Zhu, W. Nanospheres of silver nanoparticles: agglomeration, surface morphology control and 
application as SERS substrates. Phys. Chem. Chem. Phys. 2009, 11 (34), $7450-7454$

(38) Liu, C. P.; Jeng, G. R. Properties of aluminum doped zinc oxide materials and sputtering thin films. J. Alloys Compd. 2009, 468 (1), 343-349.

(39) Hasanpoor, M.; Aliofkhazraei, M.; Delavari, H. Microwaveassisted Synthesis of Zinc Oxide Nanoparticles. Procedia Mater. Sci. 2015, 11, 320-325.

(40) Peiris, T. A. N.; Sagu, J. S.; Hazim Yusof, Y.; Wijayantha, K. G. U. Microwave-assisted Low Temperature Fabrication of $\mathrm{ZnO}$ Thin Film Electrodes for Solar Energy Harvesting. Thin Solid Films 2015, 590, 293-298.

(41) Meire, M.; Van Der Voort, P.; Van Driessche, I.; Lommens, P. Microwave assisted synthesis of mesoporous titania and relevant surface interactions with dye molecules. Belgian Ceram. Soc. Annu. Meet. Abstr. 2014.

(42) Farzadi, A.; Solati-Hashin, M.; Bakhshi, F.; Aminian, A. Synthesis and characterization of hydroxyapatite/ $\beta$-tricalcium phosphate nanocomposites using microwave irradiation. Ceram. Int. 2011, 37 (1), 65-71.

(43) Zhao, B.; Tang, L.; Wang, B.; Liu, B.; Feng, J. Optical and electrical characterization of gradient AZO thin film by magnetron sputtering. J. Mater. Sci.: Mater. Electron. 2016, 27, 1-5.

(44) Mkawi, E. M.; Ibrahim, K.; Ali, M. K. M.; Farrukh, M. A.; Mohamed, A. S. The effect of dopant concentration on properties of transparent conducting $\mathrm{Al}$-doped $\mathrm{ZnO}$ thin films for efficient Cu2ZnSnS4 thin-film solar cells prepared by electrodeposition method. Appl. Nanosci. 2015, 5 (8), 993-1001.

(45) Wojnarowicz, J.; Kusnieruk, S.; Chudoba, T.; Gierlotka, S.; Lojkowski, W.; Knoff, W.; Lukasiewicz, M. I.; Witkowski, B. S.; Wolska, A.; Klepka, M. T.; et al. Paramagnetism of cobalt-doped $\mathrm{ZnO}$ nanoparticles obtained by microwave solvothermal synthesis. Beilstein J. Nanotechnol. 2015, 6 (1), 1957-1969.

(46) Jun, M.-C.; Park, S.-U.; Koh, J.-H. Comparative studies of Aldoped $\mathrm{ZnO}$ and Ga-doped $\mathrm{ZnO}$ transparent conducting oxide thin films. Nanoscale Res. Lett. 2012, 7 (1), 639.

(47) Sanon, G.; Rup, R.; Mansingh, A. Growth and characterization of tin oxide films prepared by chemical vapour deposition. Thin Solid Films 1990, 190 (2), 287-301.

(48) Malik, A.; Sêco, A.; Fortunato, E.; Martins, R. New UVenhanced solar blind optical sensors based on monocrystalline zinc sulphide. Sens. Actuators, A 1998, 67 (1-3), 68-71.

(49) Ruske, F.; Roczen, M.; Lee, K.; Wimmer, M.; Gall, S.; Hüpkes, J.; Hrunski, D.; Rech, B. Improved electrical transport in Al-doped zinc oxide by thermal treatment. J. Appl. Phys. 2010, 107 (1), 013708.

(50) Erhart, P.; Albe, K. First-principles study of migration mechanisms and diffusion of oxygen in zinc oxide. Phys. Rev. B: Condens. Matter Mater. Phys. 2006, 73 (11), 115207.

(51) Kykyneshi, R. Pulsed laser deposition and thin film properties of p-type barium copper sulfur fluoride, barium copper selenium fluoride, barium copper tellurium fluoride and n-type zinc indium oxide wide band-gap semiconductors, 2007.

(52) Kuo, S.-Y.; Chen, W.-C.; Lai, F.-I.; Cheng, C.-P.; Kuo, H.-C.; Wang, S.-C.; Hsieh, W.-F. Effects of doping concentration and annealing temperature on properties of highly-oriented $\mathrm{Al}$-doped $\mathrm{ZnO}$ films. J. Cryst. Growth 2006, 287 (1), 78-84.

(53) ZnO Nanocrystals and Allied Materials; Rao, M. S. R., Okada, T., Eds.; Springer Series in Materials Science; Springer India: New Delhi, 2014; Vol. 180

(54) Chen, C.-C.; Wu, H.-C. Electronic Structure and Optical Property Analysis of $\mathrm{Al} / \mathrm{Ga}$-Codoped $\mathrm{ZnO}$ through First-Principles Calculations. Materials 2016, 9 (3), 164.

(55) Ebrahimifard, R.; Golobostanfard, M. R.; Abdizadeh, H. Sol-gel derived $\mathrm{Al}$ and $\mathrm{Ga}$ co-doped $\mathrm{ZnO}$ thin films: An optoelectronic study. Appl. Surf. Sci. 2014, 290, 252-259.

(56) Mousavi, S. H.; Müller, T. S.; de Oliveira, P. W. The effects of the aluminium concentration on optical and electrical properties of AZO thin films as a transparent conductive layer. J. Mater. Sci.: Mater. Electron. 2013, 24 (9), 3338-3343.
(57) Vorobyeva, N. A.; Rumyantseva, M. N.; Vasiliev, R. B.; Kozlovskiy, V. F.; Soshnikova, Y. M.; Filatova, D. G.; Zaytsev, V. B.; Zaytseva, A. V.; Gaskov, A. M. Doping effects on electrical and optical properties of spin-coated $\mathrm{ZnO}$ thin films. Vacuum 2015, 114, 198204.

(58) Isherwood, P. J. M.; Neves, N.; Bowers, J. W.; Newbatt, P.; Walls, J. M. High quality aluminium doped zinc oxide target synthesis from nanoparticulate powder and characterisation of sputtered thin films. Thin Solid Films 2014, 566, 108-114.

(59) Chang, J. F.; Hon, M. H. The effect of deposition temperature on the properties of Al-doped zinc oxide thin films. Thin Solid Films 2001, 386 (1), 79-86. 